\title{
Polymerization of Sulfur-Containing Aldehydes. II. Polymerization with Organoaluminum Compounds
}

\author{
Noboru Yamamoto and Iwao Yamashita \\ Government Industrial Research Institute, Osaka, Midorigaoka 1, \\ Ikeda, Osaka, Japan.
}

(Received January 10, 1972)

\begin{abstract}
Polymerization of five higher aldehydes having a thioether bond represented by the formula, $\mathrm{RSCHR}^{\prime} \mathrm{CH}_{2} \mathrm{CHO}$, wherein $\mathrm{R}, \mathrm{CH}_{3}, \mathrm{C}_{2} \mathrm{H}_{5}, \mathrm{C}_{6} \mathrm{H}_{5}$, and $\mathrm{R}^{\prime}, \mathrm{H}$, $\mathrm{CH}_{3}$ were carried out at $-78^{\circ} \mathrm{C}$ with the use of several organoaluminum catalysts. In the polymerization with $\mathrm{AlEt}_{3}$ resinous polymers with polyacetal structures were produced, accompanied with a small proportion of ester. Poly ( $\beta$-methylthiobutyraldehyde) and poly ( $\beta$-ethylthiobutyraldehyde) were completely soluble in tetrahydrofuran, while poly ( $\beta$-methylthiopropaldehyde) and poly ( $\beta$-phenylthiobutyraldehyde) were almost insoluble in the usual organic solvents. These novel polyaldehydes were superior in thermal stability to polyacetaldehyde and other higher aldehyde polymers. Modified orgonoaluminum catalysts prepared by the reaction of $\mathrm{AlEt}_{3}$ with various organic compounds gave results similar to those obtained in the polymerization with $\mathrm{AlEt}_{3}$ itself. On the other hand, polymerization with $\mathrm{AlEt}_{3}$-crotonic acid catalyst system gave the cyclic trimer as main products.
\end{abstract}

KEY WORDS Aldehyde Polymerization / Sulfur-Containing Aldehyde / Poly(sulfur-containing aldehyde) / Triethyl Aluminum / Organoaluminum Catalyst / Tischchenko Reaction /

As is well known in the polymerization of higher aliphatic aldehydes including acetaldehyde, $\mathrm{AlEt}_{3}$ catalyst affords both the crystalline isotactic polymer and the amorphous polymers. The ratio of both parts was influenced by several complicated factors including the monomer structure, ${ }^{1}$ the condition of the catalyst $^{2}$, aging of catalyst ${ }^{2,3}$, concentration of catalyst $^{2,4}$, additives ${ }^{5,6}$ and impurities ${ }^{2,4}$. On the other hand, it has frequently been reported that the catalyst systems prepared by reaction of $\mathrm{AlEt}_{3}$ with various compounds, alcohols ${ }^{7}$, alkali hydroxides $^{8}$, sodium acetate ${ }^{9}$, alkali polyphosphates $^{6}$, and acid amides ${ }^{10}$, afford exclusively or almost the crystalline polymers.

In an attempt to polymerize some sulfur-containing aldehydes using organoaluminum compounds as initiators, characteristic features, which have not been observed in the polymerization of usual aliphatic higher aldehydes such as acetaldehyde, propionaldehyde and $n$-butyraldehyde were found. In general, the polymers produced were amorphous or slightly crystalline and completely or partly soluble in tetrahydro- furan (THF), A small proportion of the ester was isolated as by-products.

\section{EXPERIMENTAL}

\section{Materials}

Monomer. Sulfur-containing aldehydes were prepared by the method described in the preceding paper.

Solvents. Commercial reagents were dried by the usual methods and distilled.

Catalysts. Commercial $\mathrm{AlEt}_{3}$ (Ethyl corp.) was used without further purification as a dilute solution in toluene. $\mathrm{Et}_{2} \mathrm{AlCl}$ and $\mathrm{Et} \mathrm{AlCl}_{2}$ were distilled under nitrogen and employed in a toluene solution. $\mathrm{AlEt}_{3}$-additive catalysts systems, were prepared by the reaction between equimolar amounts of $\mathrm{AlEt}_{3}$ and the various additives in toluene. The reaction mixtures were kept at room temperature for $24 \mathrm{hr}$ bofore use. The compounds containing active hydrogens in their structures, which quantitatively reacts with $\mathrm{AlEt}_{3}$ at room temperature to give ethane, e.g., aniline ${ }^{11}$, isopropanol ${ }^{7}, t$-buthanol $^{7}$, 
ethanethiol, and water ${ }^{5}$ were selected as additives. Diethyl disulfide and sodium tripolyphosphate were also used as additives for the purpose of comparison. Liquid compounds used as additives were dried by ordinary methods and rectified under nitrogen. Sodium tripolyphosphate was dried at $100^{\circ} \mathrm{C}$ under a reduced pressure.

\section{Polymerization and Separation Method}

The procedure is illustrated by the following example, in which $\beta$-methylthiopropaldehyde (MTPA) was polymerized by $\mathrm{AlEt}_{3}$. The apparatus described in the preceding paper was employed. Prior to use, the polymerization tube was rinsed with $1-\%$ solution of sodium hydroxide in water, washed with water and dried by heating under reduced pressure. A mixture of $5.2 \mathrm{~g}(0.05 \mathrm{~mol})$ of monomer and 10 $\mathrm{m} l$ of solvent was placed in the tube and cooled at $-30^{\circ} \mathrm{C}$. After adding $0.25 \mathrm{ml}$ of the catalyst solution in toluene $(\mathrm{g} / 20 \mathrm{~m} l)$ to the monomer solution under nitrogen atmosphere, the mixture was kept at $-78^{\circ} \mathrm{C}$ for $24 \mathrm{hr}$. Methanol $(10 \mathrm{ml})$ containing a small proportion of water was then added to the polymerization system at the same temperature. A white resinous mass, which separated as the methanolinsoluble residue, was filtered, washed with a large amount of methanol, dried under reduced pressure and then fractionated with ethyl ether and with THF at room temperature, successively. Each fraction was purified by reprecipitation. The methanol-soluble parts were poured into water and the separated organic layer extracted with ethyl ether and dried with anhydrous sodium sulfate. After removal of the ethyl ether, the residue was again extracted with petroleum ether. Solvents and unchanged monomer were then removed by distillation under reduced pressure. The residue, a viscous liquid, was shown to be the ester by infrared analysis.

\section{Characterization of Products}

The intrinsic viscosity of the polymers was determined at $30^{\circ} \mathrm{C}$ in THF using an Ubbelohde dilute viscometer. Infrared spectra were recorded on film or powder samples of the polymers. The X-ray diffraction diagrams were obtained by the powder method.
The end-capping of polymers was accomplished by the acetic anhydride-pyridine method. The reaction was carried out at $100^{\circ} \mathrm{C}$ for $3 \mathrm{hr}$ with stirring. After cooling the solution was poured into ice water, the acetylated polymers were washed with ethanol, dried, and then dissolved in THF, and reprecipitated by water. There was no weight loss during the acetylation if the volume ratio of acetic anhydride to pyridine was below $1 / 10$.

The thermal stability of the polymers was examined by the measurement of the weight loss at $100^{\circ} \mathrm{C}$ and at $150^{\circ} \mathrm{C}$ in air, or under reduced pressure after a fixed time of heating. The TGA and DTA curves were measured using Rigaku Denki thermogravimetric and differential thermal analyzers.

\section{RESULTS AND DISCUSSION}

\section{Polymerization by $\mathrm{AlEt}_{3}$}

Effect of Solvents. The results of the bulk polymerization using $\mathrm{AlEt}_{3}$ as initiator are given in Table I. The data of the experiments carried out in solvents are shown in Table II.

Table I. Bulk polymerization of sulfurcontaining aldehydes by $\mathrm{AlEt}_{3}{ }^{\mathrm{a}}$

\begin{tabular}{|c|c|c|c|c|}
\hline \multirow{2}{*}{ Monomer } & \multirow{2}{*}{$\begin{array}{l}\text { Catalyst/ } \\
\text { Monomer, } \\
\text { mol } \%\end{array}$} & \multirow{2}{*}{$\begin{array}{c}\text { Ester } \\
\text { yield, } \\
\%\end{array}$} & \multicolumn{2}{|c|}{ Polymer } \\
\hline & & & Yield, \% & {$[\eta], \mathrm{d} l / \mathrm{g}$} \\
\hline MTPA & 1.5 & 7 & 37 & \\
\hline ETPA & 1.4 & 7 & 62 & \\
\hline MTBA & 1.7 & 1 & 57 & \\
\hline МТВА & 3.0 & & 40 & 6.8 \\
\hline ETBA & 1.0 & & 14 & 6.6 \\
\hline ETBA & 1.9 & & 16 & 6.7 \\
\hline ETBA & 3.8 & 18 & 48 & 5.6 \\
\hline PTBA & 1.5 & 5 & 27 & \\
\hline
\end{tabular}

a Monomer, $5 \mathrm{~g}$; temp, $-78^{\circ} \mathrm{C}$; time, $24 \mathrm{hr}$.

Table III shows the results obtained by fractionation of the products. In all cases, when the catalyst solution was added to the cold monomer solution, a green-yellow colour developed which instantly disappeared when the solution was shaken. The solution became gradually viscous and soldified within $3 \mathrm{hr}$ without phase separation. In THF, the apparent polymerization rate as well as polymer yield were very low 
N. YAmAmoto and I. Yamashita

Table II. Polymerization by $\mathrm{AlEt}_{3}{ }^{\mathrm{a}}$

\begin{tabular}{llcccc}
\hline Monomer & Solvent & $\begin{array}{c}\text { Catalyst/Monomer, } \\
\text { mol } \%\end{array}$ & $\begin{array}{c}\text { Polymerization } \\
\text { time, day }\end{array}$ & $\begin{array}{c}\text { Ester } \\
\text { yield, } \%\end{array}$ & $\begin{array}{c}\text { Polymer } \\
\text { yield, } \%\end{array}$ \\
\hline MTPA & Toluene & 1 & 1 & 12 & 63 \\
ETPA & Toluene & 1 & 1 & 6 & 71 \\
ETPA & THF & 4 & 2 & 2 & 12 \\
MTBA & Toluene & 1 & 1 & 2 & $88^{b}$ \\
MTBA & $\mathrm{CH}_{2} \mathrm{Cl}_{2}$ & 2 & 1 & 15 & 52 \\
MTBA & THF & 4 & 2 & 3 & 0 \\
ETBA & Toluene & 1 & 1 & 6 & $83^{\mathrm{c}}$ \\
ETBA & $\mathrm{CH}_{2} \mathrm{Cl}_{2}$ & 2 & 1 & 3 & 65 \\
ETBA & $\mathrm{THE}_{\text {THE }}$ & 4 & 2 & 4 & 26 \\
PTBA & Toluene & 1 & 1 & 6 & 52 \\
\hline
\end{tabular}

a Monomer, $0.05 \mathrm{~mol}$; solvent, $12 \mathrm{ml}$; temp, $-78^{\circ} \mathrm{C}$.

b $[\eta]=4.8$, in $\mathrm{THF}$ at $30^{\circ} \mathrm{C}$.

c $[\eta]=6.8$, in $\mathrm{THF}$ at $30^{\circ} \mathrm{C}$.

Table III. Results of fractionation of polymers

\begin{tabular}{|c|c|c|c|c|c|}
\hline \multirow{2}{*}{ Polymer } & \multicolumn{2}{|c|}{ Ether-soluble } & \multicolumn{2}{|c|}{ Ether-insoluble and THF-soluble } & \multirow{2}{*}{ 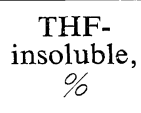 } \\
\hline & $\%$ & {$[\eta], \mathrm{d} l / \mathrm{g}$} & $\%$ & {$[\eta], \mathrm{d} l / \mathrm{g}$} & \\
\hline PolyMTPA $^{\mathrm{a}}$ & 12 & 0.6 & 18 & 1.5 & 70 \\
\hline PolyMTPA $^{\mathrm{b}}$ & 10 & 0.7 & 26 & 1.2 & 64 \\
\hline PolyPTPA $^{a}$ & 5 & 0.3 & 39 & 8.5 & 56 \\
\hline PolyPTPA ${ }^{b}$ & 0 & & 38 & 9.0 & 62 \\
\hline
\end{tabular}

a obtained in bulk polymerization.

$\mathrm{b}$ obtained in polymerization in toluene.

and a much higher concentration catalyst was required to obtain polymer. Poor polymer yield in this case may be explained by the coordination affinity of the THF to the aluminum. It is likely that the high coordinating ability of the oxygen in THF to the catalyst aluminum relatively weakens the coordination of the monomer carbonyl oxygen to the aluminum.

Effect of Catalyst Addition Temperature. In cases where relatively small quantities of initiator (below 1 mol\% to monomer) were employed and in which the catalyst solutions were added to monomer precooled to $-78^{\circ} \mathrm{C}$, polymer in poor yield or no polymer at all was obtained. However, if the temperature in the same system was once increased to room temperature, and then cooled again to $-78^{\circ} \mathrm{C}$, polymer was obtained in higher yield. In addition, when the same amount of catalyst solution was added to monomer at $-25^{\circ} \mathrm{C}$ and the mixture kept at the same temperature for $10 \mathrm{~min}$, and then cooled to $-78^{\circ} \mathrm{C}$, the polymerization was smoothly initiated and the polymer was also obtained in good yield. These observations have been pointed out in the case of acetaldehyde polymerization by Ishida ${ }^{2}$. From such facts, it may be supposed that the real active species in polymerizations with $\mathrm{AlEt}_{3}$ are reaction products of $\mathrm{AlEt}_{3}$ with monomer or with impurity.

Polymerization with $\mathrm{AlEt}_{3}$-Additive System Catalysts

The results of polymerization using various modified organoaluminum catalysts are summarized in Table IV. It is well known that compounds having active hydrogen, e.g., water, alcohol, thiol, and aniline react quantitatively with $\mathrm{AlEt}_{3}$ to produce new organoaluminum compouds containing metal-hetero atom bonds, $-\mathrm{Al}-\mathrm{O},-\mathrm{Al}-\mathrm{S},-\mathrm{Al}-\mathrm{N}^{7,11}$. In polymerizations initiated by these catalysts at $-78^{\circ} \mathrm{C}$, an induction period was generally observed, but 
Polymerization of Sulfur-Containing Aldehydes by Organoaluminum

Table IV. Results of polymerization by various $\mathrm{AlEt}_{3}$-additive catalyst systems ${ }^{2}$

\begin{tabular}{|c|c|c|c|c|c|c|}
\hline Monomer & Additive & Additive/AlEt ${ }_{3}$ & $\mathrm{AlEt}_{3} /$ Monomer & $\begin{array}{l}\text { Ester } \\
\text { yield, \% }\end{array}$ & $\begin{array}{l}\text { Polymer } \\
\text { yield, } \%\end{array}$ & $\begin{array}{l}{[\eta]} \\
\mathrm{d} l / \mathrm{g}\end{array}$ \\
\hline ETBA & TPP-Na ${ }^{b}$ & 1 & 3.8 & 4 & 48 & 6.5 \\
\hline " & " & 0.5 & 3.8 & 8 & 52 & 5.4 \\
\hline " & $\mathrm{C}_{2} \mathrm{H}_{5} \mathrm{SSC}_{2} \mathrm{H}_{5}$ & 1 & 3.8 & & 18 & 4.9 \\
\hline$" \prime$ & $\mathrm{C}_{2} \mathrm{H}_{5} \mathrm{SH}$ & 1 & 3.8 & & 32 & 12.9 \\
\hline$" 1$ & $t-\mathrm{C}_{4} \mathrm{H}_{9} \mathrm{OH}$ & 1 & 1 & & 70 & 6.0 \\
\hline$" \prime$ & $\mathrm{C}_{6} \mathrm{H}_{5} \mathrm{NH}_{2}$ & 0.5 & 3.8 & & 35 & \\
\hline MTBA & TPP-Na & 1 & 2 & & 75 & \\
\hline " & $t-\mathrm{C}_{4} \mathrm{H}_{9} \mathrm{OH}$ & 1 & 3 & & 79 & 7.0 \\
\hline " & " & 2 & 3 & & 77 & 5.9 \\
\hline " & $\mathrm{H}_{2} \mathrm{O}$ & 0.5 & 1 & 2 & 45 & \\
\hline " & "I & 1 & 1 & Trace & 48 & \\
\hline " & " & 2 & 1 & " & 53 & \\
\hline ETPA & $t-\mathrm{C}_{4} \mathrm{H}_{9} \mathrm{OH}$ & 1 & 2 & 10 & 50 & \\
\hline " & $\mathrm{C}_{2} \mathrm{H}_{5} \mathrm{SH}$ & 1 & 2 & 4 & 46 & \\
\hline
\end{tabular}

a Monomer, $0.05 \mathrm{~mol}$; toluene, $10 \mathrm{ml}$; temp, $-78^{\circ} \mathrm{C}$; time, $24 \mathrm{hr}$.

b TPP-Na, sodium tripolyphosphate.

not in the case of the addition at room temperature. The polymerization rate was less than that in the polymerization using $\mathrm{AlEt}_{3}$ only, for example, the time-conversion curve in the polymerization of $\beta$-ethylthiobutyraldehyde (ETBA) with $\mathrm{AlEt}_{3}-t$-butanol-(1: 1) as initiator is shown in Figure 1 compared with data for the polymerization using $\mathrm{AlEt}_{3}$.

Both polymer yield and solubility in THF of the polymers produced were not very different from the results obtained in the $\mathrm{AlEt}_{3}$-initiated polymerization. The addition of sodium tri-

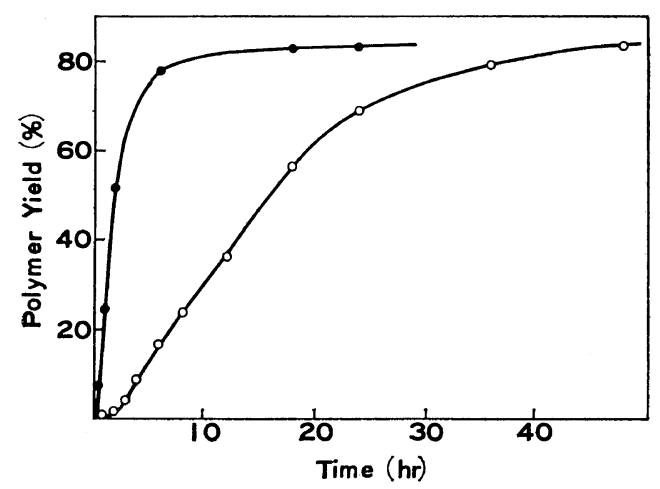

Figure 1. Time-yield curve in the polymerization of ETBA: monomer, $0.05 \mathrm{~mol}$; toluene, 12 $\mathrm{m} l$; catalyst, $\bigcirc$, triethylaluminum, $\bigcirc$, triethylaluminum-t-butanol-(1: 1), $0.0005 \mathrm{~mol}$; temp, $-78^{\circ} \mathrm{C}$. polyphosphate and diethyl disulfide hardly affected the polymerization rate.

\section{Polymerization with Alkylaluminum Chlorides}

The results of the polymerization of $\beta$-methylthiobutyraldehyde (MTBA) with alkylaluminum chloride catalysts are given in Table V. The

Table V. Polymerization of MTBA by chlorinecontaining aluminum compounds ${ }^{a}$

\begin{tabular}{lccc}
\hline Catalyst & $\begin{array}{c}\text { Catalyst/Monomer, } \\
\text { mol \% }\end{array}$ & Solvent & $\begin{array}{c}\text { Polymer } \\
\text { yield, \% }\end{array}$ \\
\hline $\mathrm{AlCl}_{3}$ & 1 & Toluene & 0 \\
$\mathrm{AlEtCl}_{2}$ & 1 & $\prime \prime$ & 3 \\
$\prime \prime$ & 2 & $\prime \prime$ & 9 \\
$\mathrm{AlEt}_{2} \mathrm{Cl}$ & 1 & $\prime \prime$ & 15 \\
$\prime \prime$ & 2 & $\mathrm{Bulk}^{\prime}$ & 28 \\
$\prime \prime$ & 2 & $\mathrm{CH}_{2} \mathrm{Cl}_{2}$ & 26 \\
\hline
\end{tabular}

a Monomer $0.05 \mathrm{~mol}$; toluene, $12 \mathrm{ml}$; temp, $-78^{\circ} \mathrm{C}$; time, $24 \mathrm{hr}$.

polymer yield decreased with increase of chlorine. $\mathrm{AlCl}_{3}$ gave only a trace of the cyclic trimer.

\section{Polymerization with $\mathrm{AlEt}_{3}$ in the Presence of Crotonic acid}

In some experiments when monomers prepared with the use of cupric acetate were employed with insufficient purification, it was observed that the cyclic trimers were isolated in addition to the linear polymer, and an ester was hardly 


\section{N. Yamamoto and I. Yamashita}

Table VI. Polymerization by $\mathrm{AlEt}_{3}$ in the presence of crotonic acid $(\mathrm{CA})^{\mathrm{a}}$

\begin{tabular}{cccrrr}
\hline Monomer & $\begin{array}{c}\mathrm{AlEt}_{3} / \text { Monomer, } \\
\text { mol \% }\end{array}$ & CA/AlEt $t_{3}$ & $\begin{array}{c}\text { Cyclic trimer } \\
\text { yield, } \%\end{array}$ & $\begin{array}{c}\text { Ester yield, } \\
\%\end{array}$ & $\begin{array}{r}\text { Polymer } \\
\text { yield, \% }\end{array}$ \\
\hline ETBA & 1 & 1 & 4 & 0 & 0 \\
" & 1 & 0.1 & 3 & 0 & 0 \\
" & 2 & 0.1 & 6 & 0 & 23 \\
"b & 1 & 0 & 0 & 6 & 83 \\
" & 1 & 1 & 53 & 0 & 2 \\
" & 2 & 0.5 & 33 & 0 & 20 \\
"b & 2 & 0.1 & 60 & 0 & 23 \\
& 1 & 0 & 0 & 5 & 71
\end{tabular}

a Monomer (distillation times, 6), $0.05 \mathrm{~mol}$; toluene, $12 \mathrm{ml}$; temp, $-78^{\circ} \mathrm{C}$; time, $48 \mathrm{hr}$.

b Time, $24 \mathrm{hr}$.

produced, even in $\mathrm{AlEt}_{3}$-induced polymerizations. This cationic feature may be attributed to acids such as crotonic acid and acrylic acid which were probably included in the raw material of the monomer, an unsaturated aldehyde. For the purpose of clarifying this presumption, polymerization by $\mathrm{AlEt}_{3}$ in the presence of crotonic acid was examined. Monomer purified by distillation was kept at $-78^{\circ} \mathrm{C}$ and then toluene containing a small amount of crotonic acid and a catalyst solution added to the monomer. As is shown in Table VI, in the case of the polymerization using monomers distilled six times, the polymers were obtained in satisfactory yields, together with an ester in a several percent yield. On the other hand, the polymerization in the presence of crotonic acid afforded the polymer in a yield of a few percent and the cyclic trimer was produced in high yields. In the polymerization of ETBA, in which $1 \mathrm{~mol} \%$ of catalyst to monomer was employed, even the addition of $0.1 \mathrm{~mol} \%$ of crotonic acid to monomer prevented the formation of linear high polymer. $\beta$-Ethylthiopropaldehyde(ETPA) yielded the cyclic trimer more readily than ETBA under these polymerization conditions. These results corresponded to those shown in the polymerization with typical cationic catalysts such as $\mathrm{AlBr}_{3}$ or $\mathrm{SnCl}_{4}$. Therefore, it supposed that the mechanism of polymerization by $\mathrm{AlEt}_{3}$ - crotonic acid is of typical cationic character unlike that of the polymerization with $\mathrm{AlEt}_{3}$ itself.

\section{Characteristic of Polymers}

The polyacetal structure of the polymers obtained was confirmed by infrared spectra, which show the same absorption bands as those polymers prepared using cationic catalysts. All polymers decomposed abruptly without melting. These results corresponded with the observations thermogravimetric analysis (Figure 2).

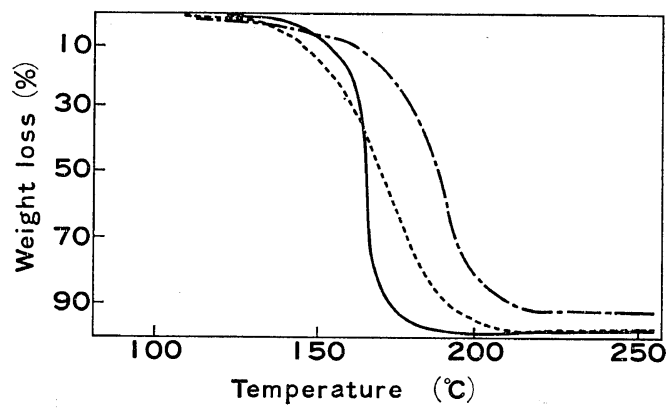

Figure 2. TGA curves of sulfur-containing aldehyde polymers: heating rate, $5^{\circ} \mathrm{C} / \mathrm{min}$ in air;

$\longrightarrow$, polyMTBA, $[\eta]=4.8$, end-capped (DTApeak, $\left.170^{\circ} \mathrm{C}\right)$;

----, polyETBA, $[\eta]=6.8$, end-capped (DTApeak, $180^{\circ} \mathrm{C}$ );

$\cdot--$, polyPTBA, $[\eta]=9.0$, uncapped (DTApeak, $180^{\circ} \mathrm{C}$ ).

PolyETBA as well as polyMTBA were white resinous materials soluble in THF at room temperature. Brittle fibrous polymers were recovered by reprecipitation with water from the polymer solution in THF. Furthermore, the polymers could be recovered from the solutions as transparent films by the gradual evaporation of 
solvent. These polymers were also soluble in trichloroethylene, dichloroethane, and toluene at their boiling points.

PolyETPA obtained with these organo aluminum catalysts were resinous materials having

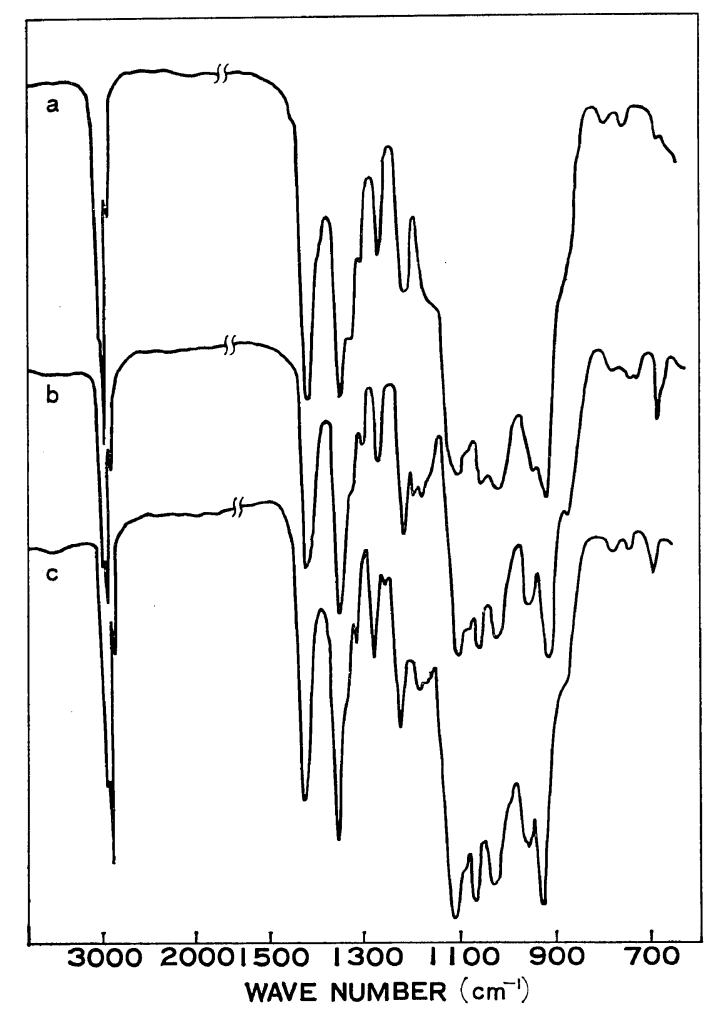

Figure 3. Infrared spectra of polyMTPA:

(a) ether-soluble fraction; (b) ether-insoluble and THF-soluble fraction; (c) THF-soluble fraction. some flexibility and insoluble in ethyl ether unlike the polymers obtained by cationic polymerizations. This polymer was also insoluble in the usual organic solvents except hot THF, but gave the same infrared spectrum as that of the ether-soluble polymer. From X-ray analysis, polyETBA, and polyETPA were found to be amorphous. However, in order to decide the steric structure of these polymers further examination will be required. The ether-soluble polyMTPA was a rubber-like material which was soluble in the usual organic solvents except petroleum ether. The ether-soluble parts of polyPTBA was a paste of low-molecular-weight polymer, also soluble in common organic solvents. The THF-insoluble parts of both polyMTPA and polyPTBA were also insoluble in other organic solvents and showed low crystallinity. The IR spectra of these ether-soluble polymers were different from those of the insoluble polymers (Figure 3). It may be supposed that the former are atactic polymer, while the latter are isotactic or stereoblock polymer by analogy with the solubilities of many other aliphatic higher-aldehyde polymers.

In general, in polymerization of ordinary higher aliphatic aldehydes, the facility of the formation of the insoluble crystalline polymer increases with increase of the bulkiness and of the length of the side chain. It is of interest that in the present case the bulkiness of the substituent gave the reverse effect on both insolubility and crystallinity of the product, as is shown by comparing polyETBA with poly-

Table VII. Thermal decomposition of polymer obtained by $\mathrm{AlEt}_{3}$

\begin{tabular}{|c|c|c|c|c|}
\hline \multirow{2}{*}{ Condition } & \multirow{2}{*}{$\begin{array}{c}\text { Time, } \\
\mathrm{hr}\end{array}$} & \multicolumn{3}{|c|}{ Weight loss $^{\mathrm{a}}, \%$} \\
\hline & & PolyMTPA $^{\mathrm{b}}$ & PolyMTBA $^{c}$ & PolyETBA $^{d}$ \\
\hline \multirow[t]{3}{*}{$100^{\circ} \mathrm{C}$, in air } & 1 & $\begin{array}{ll}0 & (0)\end{array}$ & $0.8(0.4)$ & $1.1(0.3)$ \\
\hline & 2 & $0.2(0)$ & $1.5(0.7)$ & $1.8(0.6)$ \\
\hline & 4 & $1.0(0)$ & $2.8(1.3)$ & $3.6(1.2)$ \\
\hline \multirow[t]{3}{*}{$100^{\circ} \mathrm{C}$, under reduced pressure $(2 \mathrm{mmHg})$} & 1 & $0 \quad(0)$ & $0.7(0.3)$ & $1.0(0.5)$ \\
\hline & 2 & $0.2(0.3)$ & $1.4(0.8)$ & $1.8(1.2)$ \\
\hline & 4 & $1.0(0.9)$ & $2.6(1.7)$ & $3.2(2.4)$ \\
\hline \multirow[t]{3}{*}{$150^{\circ} \mathrm{C}$, under reduced pressure $(2 \mathrm{mmHg})$} & 1 & & $43.0(10.0)$ & $36.0(7.5)$ \\
\hline & 2 & & $56.5(18.5)$ & $50.0(15.0)$ \\
\hline & 4 & & $70.0(31.0)$ & $61.0(27.0)$ \\
\hline
\end{tabular}


MTPA. The results of the thermal stability test are shown in Table VII. These polymers were thermally much more stable than other polyaldehydes except polyformaldehyde. For example, polyETBA showed only $0.7-\%$ weight decrease after $5 \mathrm{hr}$ at $100^{\circ} \mathrm{C}$ in air, while polyacetaldehyde completely decompose to monomer under the same conditions. The good stability of these sulfur-containing polyaldehydes may be ascribed mainly to the shielding effect of the sulfide group against the attack of oxygen or acidic substances on the polyacetal chain. The stability of these polymers was further improved by acetylation and by addition of basic polymer compounds such as sodium polyphosphate, carboxy methyl cellulose sodium salt and other basic carbohydrate analogs.

\section{By-Products}

The infrared spectra of the by-products collected from the petroleum ether extracts commonly show strong characteristic absorption band in $1740 \mathrm{~cm}^{-1}$ attributed to an ester carbonyl group and those due to single carbonoxygen bond of an ester group at 1200-1250 $\mathrm{cm}^{-1}$ and $1000-1050 \mathrm{~cm}^{-1}$. These esters were shown to be the dimeric ester, $\mathrm{RCOOCH}_{2} \mathrm{R}$, formed by the Tischchenko reaction. As an example, the characterization of $\gamma$-ethylthiobutyl$\beta$-ethylthiobutyrate $\mathrm{C}_{2} \mathrm{H}_{5} \mathrm{SCH}\left(\mathrm{CH}_{3}\right) \mathrm{CH}_{2} \mathrm{COOCH}_{2}$ $\mathrm{CH}_{2} \mathrm{CH}\left(\mathrm{CH}_{3}\right) \mathrm{SC}_{2} \mathrm{H}_{5}$, the by-product obtained from ETBA was shown as follows:

bp $118^{\circ} \mathrm{C}(0.4 \mathrm{~mm}) ; n_{\mathrm{D}}^{20} 1.4917 ; M W$ (VPO in benzene) 267 (calcd 264.4).

Elemental analysis Found: C, 54.41; H, 9.27;

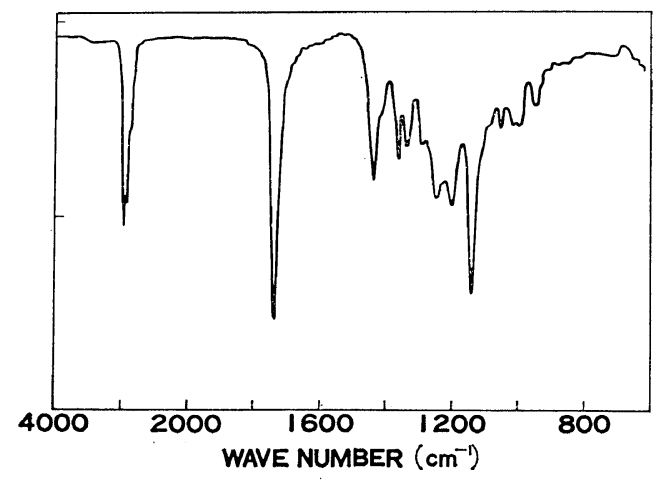

Figure 4. Infrared spectrum of the dimeric ester of ETBA.
S, 24.39. Calcd: C, 54.50; H, 9.14; S, 24.25. NMR $\delta 1.28\left(\mathrm{t}, \mathrm{CH}_{3} \mathrm{CH}_{2}\right), 1.32\left(\mathrm{~d}, \mathrm{CH}_{3} \mathrm{CH}\right)$, 2.99-3.15 (s, $\left.\mathrm{CH}_{2}\right), 2.22-3.0\left(\mathrm{~s}, \mathrm{SCH}_{2}+\overline{\mathrm{CH}}_{2} \mathrm{C}=\right.$ $\mathrm{O}), 2.99-3.15$ (s, CHS), and $4.20 \mathrm{ppm}\left(\mathrm{t}, \mathrm{OCH}_{2}\right)$. The IR spectrum is illustrated in Figure 4.

Formation of such an ester under polymerization conditions may reasonably be explained with the mechanism proposed by Furukawa, et al. ${ }^{1}$

\section{Special Features of Polymerization of Sulfur- Containing Aldehyde}

As is well known, in the polymerization of acetaldehyde, typical cationic catalysts give only the amorphous atactic polymer, while $\mathrm{AlEt}_{3}$ produces both the crystalline isotactic and the amorphous polymers.

On the other hand, aliphatic higher-aldehydes having more than three carbon atoms polymerized to the partly crystalline isotactic polymers, even if typical Lewis acids such as $\mathbf{B F}_{3} \mathrm{OEt}_{2}$ and $\mathrm{AlBr}_{3}$ were employed as calalyst. In addition, it has been reported that isobutyraldehyde and $n$-heptaldehyde were converted to the crystalline polymer even in high-pressure polymerization, in which acetaldehyde and $n$-butyraldehyde produce the rubber-like polymer ${ }^{12}$.

From the above facts, it may be generally concluded that the crystallinity or solubility and stereoregularity of polymers formed in aldehyde polymerization were firstly affected by monomer structure, and slightly by the nature of catalyst used. The conclusion was also found to be true for the polymerization of sulfurcontaining aldehydes.

On the whole, in the case of the polymerization of sulfur-containing aldehydes both the infrared spectra and solubility of polymers obtained by the use of $\mathrm{AlEt}_{3}$ were found to be identical with those of polymers prepared by typical cationic catalysts, $\mathrm{SnCl}_{4}$ or $\mathrm{AlBr}_{3}$. Moreover, even in the polymerization by the $\mathrm{AlEt}_{3}$ additive system catalysts, which gave selectively the isotarctic crystalline polymer in acetaldehyde polymerization, crystallinity and solubility of the produced sulfur-containing polyacetal did not differ from the results obtained in the $\mathrm{AlEt}_{3}$ initiated polymerization.

A remarkable difference was found with regard to the by-product between two catalyst 
systems, cationic and organoaluminum. That is, in the polymerization by the former, the by-product was the cyclic trimer, while in the polymerization using the latter the dimeric ester was obtained. From these facts, it may be likely that the $\mathrm{AlEt}_{3}$-initiated polymerization of sulfur-containing aldehydes proceeds by a coordinate anionic mechanism ${ }^{1}$.

The polymerization mechanism will be discussed further in the following papers.

Ackowledgement. The authors wish to thank professor T. Tsuruta of Tokyo university for many helpful discussions.

\section{REFERENCES}

1. J. Furukawa, T. Saegusa, H. Fujii, A. Kawasaki, H. Imai, and Y. Fujii, Makromol. Chem., 37, 149 (1960); 44/46, 398, (1960).

2. S. Ishida, J. Polym. Sci., 62, 1 (1962); Kobunshi Kagaku (Chem. High Polymers), 18, 189 (1961).
3. H. Fujii, I. Tsukuma, T. Saegusa, and J. Furukawa, Makromol. Chem., 82, 32 (1965).

4. H. Tani, et al., abstract, SPSJ 17th Symposium on Macromolecules, Matsuyama, Oct., 1968, pp 503-507.

5. T. Saegusa, H. Fujii, Y. Fujii, and J. Furukawa, Makromol. Chem., 55232 (1962).

6. T. Miyakawa, N. Yamamoto, and Y. Takemoto, Kogyo Kagaku Zasshi (J. Chem. Soc. Japan, Ind. Chem. Sect.), 66, 1703 (1963).

7. J. Furukawa, T. Saegusa, and H. Fujii, $J$. Polym. Sci., Part C, 4, 281 (1963).

8. H. Tani, T. Aoyagi, and T. Araki, ibid. Part B, 2, 921 (1964).

9. S. Ohta, H. Fujii, F. Saegusa, and J. Furukawa, Kogyo Kagaku Zasshi (J. Chem. Soc. Japan, Ind. Chem. Sect.), 66, 1484 (1963).

10. H. Tani, H. Yasuda, and T. Araki, J. Polym. Sci., Part B, 2, 933 (1964).

11. C. Longiave and R. Castelli, ibid., Part C, 387 (1963).

12. A. Novak and E. Whalley, Can. J. Chem., 37, 1710 and 1718 (1959). 